\title{
Elevated endothelin-1 level is a risk factor for nonocclusive mesenteric ischemia
}

\author{
Heinrich V. Groesdonk, MD, ${ }^{\mathrm{a}, \mathrm{b}}$ Miriam Raffel, MD, ${ }^{\mathrm{a}}$ Thimoteus Speer, MD, PhD, ${ }^{\mathrm{c}}$ Hagen Bomberg, MD, ${ }^{\mathrm{a}, \mathrm{b}}$ \\ Wolfram Schmied, Dipl Psych, ${ }^{a}$ Matthias Klingele, $M D,{ }^{c}$ and Hans-Joachim Schäfers, MD $^{\mathrm{a}}$
}

\begin{abstract}
Objective: Nonocclusive mesenteric ischemia may occur after cardiac surgery, commonly in conjunction with the use of cardiopulmonary bypass. Some evidence suggests that endothelin-1 serum levels are increased in patients with mesenteric ischemia, but the association of endothelin-1 and nonocclusive mesenteric ischemia has not been studied. The objective was to investigate whether elevated levels of endothelin- 1 could be found in patients exhibiting nonocclusive mesenteric ischemia.
\end{abstract}

\begin{abstract}
Methods: In an observational cohort study, nonocclusive mesenteric ischemia developed in 78 of 865 patients undergoing elective cardiac surgery. Control patients were identified from the cohort through 1:1 propensity score matching. Preoperative and postoperative endothelin-1 serum levels were determined by means of enzymelinked immunosorbent assay. Odds ratios (with $95 \%$ confidence interval) were calculated by logistic regression analyses to determine the risk of endothelin- 1 for the development of nonocclusive mesenteric ischemia.
\end{abstract}

Results: Patients with nonocclusive mesenteric ischemia had higher preoperative (11.3 vs $9.3 \mathrm{pg} / \mathrm{mL} ; P=.001)$ and postoperative $(15.7 \mathrm{vs} 11.1 \mathrm{pg} / \mathrm{mL}, P<.001)$ levels of endothelin- 1 than the controls. The probability of developing nonocclusive mesenteric ischemia increased with each picogram/milliliter endothelin-1 level preoperatively (odds ratio, 1.29; 95\% confidence interval, 1.12-1.49) and each picogram $/ \mathrm{milliliter}$ postoperatively (odds ratio, 2.04; 95\% confidence interval, 1.54-2.72). Receiver operating characteristic analyses showed that elevated endothelin- 1 serum levels had a high accuracy to predict nonocclusive mesenteric ischemia (optimal cutoff value of $14.5 \mathrm{pg} / \mathrm{mL}$, area under the curve of 0.77 , sensitivity $51 \%$, and specificity $94 \%$ ).

Conclusions: Endothelin-1 seems to predispose patients undergoing cardiac surgery to develop nonocclusive mesenteric ischemia. In addition, it may be a useful marker to identify patients at risk for nonocclusive mesenteric ischemia after cardiac surgery. (J Thorac Cardiovasc Surg 2015;149:1436-42)

See related commentary pages $1443-4$.

Supplemental material is available online.

Nonocclusive mesenteric ischemia (NOMI) is a dreaded gastrointestinal complication after cardiopulmonary bypass (CPB) with mortality rates of up to $90 \%{ }^{1,2}$ It is considered as a form of intestinal blood flow impairment with

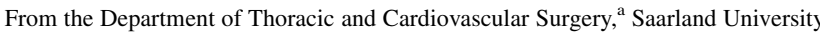
Medical Center, Homburg/Saar, Germany; Department of Anesthesiology, ${ }^{b}$ Intensive Care Medicine and Pain Medicine, Saarland University Medical Center, Homburg/Saar, Germany; and Division of Nephrology and Hypertension, Department of Medicine, ${ }^{\mathrm{c}}$ Saarland University Medical Center, Homburg/Saar, Germany.

Disclosures: Heinrich V. Groesdonk reports lecture fees from Novartis, Mitsubishi, and MSD. Matthias Klingele reports lecture fees from Baxter and Fresenius Medical Care. All other authors have nothing to disclose with regard to commercial support.

Received for publication April 21, 2014; revisions received Nov 17, 2014; accepted for publication Dec 6, 2014; available ahead of print Jan 23, 2015

Address for reprints: Hans-Joachim Schäfers, MD, Department of Thoracic and Cardiovascular Surgery, University Medical Center, University of Saarland, Kirrbergerstraße 1, 66421 Homburg/Saar, Germany (E-mail: h-j.schaefers@uks.eu).

$0022-5223 / \$ 36.00$

Copyright (c) 2015 by The American Association for Thoracic Surgery http://dx.doi.org/10.1016/j.jtcvs.2014.12.019 extreme reduction or maldistribution of splanchnic blood flow. $^{2,3}$ Intestinal ischemia leads to compromised mucosal integrity, bacterial translocation, bacteremia, and the development of multiorgan failure. Nevertheless, the exact pathomechanism leading to nonocclusive disease is currently unknown. ${ }^{2}$

We have previously identified perioperative risk factors for the development of NOMI after cardiac surgery, such as the use of an intra-aortic balloon pump, catecholamine support, or loss of sinus rhythm. ${ }^{4}$ However, these risk factors are not apparently related to common physiologic mechanisms that are important to understand if NOMI is to be prevented.

In a porcine model, experimental application of endothelin (ET)-1 has been shown to reduce microvascular blood flow of the distal jejunum and ileum. ${ }^{5}$ Specific $\mathrm{ET}_{\mathrm{A}}$ and $\mathrm{ET}_{\mathrm{B}}$ blockade with tezosentan were shown to improve microcirculatory blood flow in the ileal mucosa during experimental endotoxemia. ${ }^{6}$ We previously observed that CPB leads to jejunal ischemia, which is associated with upregulation of ET-1 and changes in ET receptor expression.

Although these observations indicated a role of ET in intraoperative visceral malperfusion, it is still unclear whether these findings are transferable to humans and to 

Abbreviations and Acronyms
$\mathrm{CI}=$ confidence interval
$\mathrm{CPB}=$ cardiopulmonary bypass
$\mathrm{ET}=$ endothelin
NOMI $=$ nonocclusive mesenteric ischemia
$\mathrm{OR}=$ odds ratio
ROC $=$ receiver operating characteristic

the setting of NOMI. If ET should be involved in human NOMI, treatment with ET receptor antagonists might become a clinical strategy. We decided to investigate whether elevated serum ET-1 levels are associated with an increased risk for the occurrence of NOMI in patients undergoing elective cardiac surgery.

\section{MATERIALS AND METHODS Patients}

After approval by the local ethics committee (Landesärztekammer des Saarlandes; Reference Identification: 199/09), a prospective cohort study was performed from January 1, 2010, to March 31, 2011. During the study period, 1272 patients underwent cardiac surgery with extracorporeal circulation, of whom 94 underwent urgent surgery and 15 underwent emergency surgery. Of the 1163 adult patients who underwent elective cardiac surgery, 298 refused participation, resulting in the study population of 865 individuals (74\%) (Table E1). Written informed consent was obtained from all patients. Blood samples were obtained prospectively on all patients at regular intervals and stored for subsequent analysis.

The majority of the individuals had an uneventful postoperative course. On the basis of clinical changes suggestive of mesenteric ischemia, angiography of the superior mesenteric artery was performed in 88 patients. ${ }^{4}$ Of these, 78 were found to have NOMI, and the results were normal in 10. To create an adequate control group, 78 patients from the whole cohort were selected by propensity score-matching analysis. The final study population thus consisted of 78 patients with NOMI and 78 patients without NOMI. In these patients, ET-1 serum levels were determined post hoc.

\section{Radiographic Analysis}

Arterial angiography was performed if NOMI was suspected. The decision to perform angiography was based on the presence of at least 2 of 4 possible clinical indicators: new onset of oliguria/anuria, abdominal distention with decreased or absent bowel sounds, serum lactate levels greater than $5.0 \mathrm{mmol} / \mathrm{L}$, metabolic acidosis (base excess $<-5 \mathrm{mmol} / \mathrm{L}$ ), or increase of vasopressor support by more than 3-fold from the end of surgery in the absence of hypovolemia. Angiography was performed only in patients with a systolic blood pressure greater than $90 \mathrm{~mm} \mathrm{Hg}$ or a cardiac index greater than $1.8 \mathrm{~L} / \mathrm{min} / \mathrm{m}^{2}$. All images were assessed by an experienced radiologist and an intensivist on consensus basis with respect to vessel morphology, reflux of contrast medium into the aorta, small bowel parenchymal contrast enhancement, and distension and the delay between arterial injection and portal vein filling. In accordance with our previously published scoring system, ${ }^{3}$ NOMI was diagnosed whenever the total score was more than 1 (Table E2).

\section{Endothelin-1 Measurements}

In the late afternoon before surgery and the early morning after surgery, blood was collected in $2.7 \mathrm{~mL}$ ethylenediaminetetraacetic acid tubes (Sarstedt AG and Co, Nümbrecht, Germany) and placed on ice until centrifugation. Blood was obtained from a peripheral vein preoperatively and a central venous line postoperatively. Serum was immediately $(<5$ minutes) separated by centrifugation $(1525 g$ for 10 minutes at $4^{\circ} \mathrm{C}$ ), filled into polypropylene tubes (Sarstedt AG and Co), and stored at $-80^{\circ} \mathrm{C}$ for further analysis. The ET- 1 concentrations and the standard curves were determined using an enzyme-linked immunosorbent assay kit (Assay Designs, Immunoassay Kit, catalog no. 900-020A, Enzo Life Sciences Inc, Farmingdale, NY) according to the manufacturer's protocol. The sensitivity of the assay was 0.41 $\mathrm{pg} / \mathrm{mL}$. All measurements were performed in duplicate by the same person on the same day.

\section{Propensity Score-Matching Analysis}

To minimize patient selection bias in this retrospective nonrandomized study, we used a propensity score-matching analysis to evaluate the effect of ET-1 on the development of NOMI. The matching was based on the results of multivariate logistic regression analysis. Control patients were identified from our database, that is, patients who underwent cardiac surgery during the same study period without developing NOMI $(\mathrm{n}=787)$. A $P$ value less than .20 was defined for selecting variables for entry into the final model. Variables were selected from epidemiologic and clinical data (Table 1) including the previously identified preoperative risk factors for NOMI. ${ }^{4}$ By using these covariables, a propensity score was calculated for each patient. Finally, each patient who had NOMI was matched to 1 patient who did not have NOMI with the closest propensity score. The maximum difference of propensity score for a matching was less than 0.05 . With this technique, comparable patient cohorts (each $\mathrm{n}=78$ ) were identified for the final analysis (NOMI and control). There were no significant differences in baseline characteristics between the propensity-matched groups (Table 1).

\section{Statistical Analysis}

All data are presented as mean \pm standard deviation or with 15 th and 85 th percentile. Data analysis was performed using SPSS Statistics 19 and R 2.10.1 for Windows (IBM, Ehningen, Germany). In the first step, chi-square tests were performed to compare patients with and without NOMI regarding dichotomous variables. For continuous variables, the differences between the 2 groups were compared with Student $t$ tests (Welch's $t$ tests in case of inhomogeneous variances). The influence of NOMI on the course of ET-1 was analyzed by analysis of variance for repeated measurements.

In the second step, odds ratios (ORs) were calculated by logistic regression analyses to determine the risk of preoperative and postoperative ET-1 to have NOMI in the cohort of 156 study patients ( 78 matched pairs). Additional models were calculated, adjusted for potential confounders (listed in Table 1). In these models, to avoid collinearity, covariates with a positive correlation greater than 0.3 were excluded.

In the third step, different receiver operating characteristic (ROC) curves were performed to evaluate the predictive power of preoperative and postoperative serum ET-1 levels for the occurrence of NOMI and 30-day mortality. The Youden Index was used to calculate optimal cutoff points for ET-1 for the prediction of NOMI.

In the fourth step, ORs were adjusted for the 7 perioperative risk factors we had previously identified ${ }^{4}$ : reexploration for bleeding, intra-aortic balloon pump support, need for more than 2 packed red blood cells, serum lactate level greater than $5 \mathrm{mmol} / \mathrm{L}$, need for norepinephrine greater than $0.1 \mu \mathrm{g} / \mathrm{kg} / \mathrm{min}$, levosimendan therapy, and loss of sinus rhythm. In these models, to avoid collinearity, covariates with a positive correlation greater than 0.3 were excluded. To evaluate the potential role of ET-1 serum levels in the pathogenesis of NOMI, we compared postoperative ET-1 serum levels of the control group (positive for at least 1 risk factor) and the NOMI group. 
TABLE 1. Group characteristics and data used for propensity matching

\begin{tabular}{|c|c|c|c|}
\hline Risk factor & $\begin{array}{c}\text { NOMI } \\
(n=78)\end{array}$ & $\begin{array}{l}\text { Control } \\
(\mathrm{n}=78)\end{array}$ & $\begin{array}{r}P \\
\text { valu }\end{array}$ \\
\hline \multicolumn{4}{|l|}{ Demographics } \\
\hline \multicolumn{4}{|l|}{ Gender $(\%)^{*}$} \\
\hline Female & $30(38)$ & $30(38)$ & 1 \\
\hline Male & $48(62)$ & $48(62)$ & 1 \\
\hline Age $(y)^{*}$ & $72.0(63-81)$ & $71.3(63-81)$ & .7 \\
\hline Weight $(\mathrm{kg})^{*}$ & $81.7(65-98)$ & $80.7(65-98)$ & .7 \\
\hline Size $(\mathrm{cm})^{*}$ & $169.0(160-178)$ & $169.8(160-180)$ & .6 \\
\hline euroSCORE $2^{*}$ & $10.6(2.8-21)$ & $11.2(3-21)$ & .8 \\
\hline Ejection fraction $(\%)^{*}$ & $54.4(35-73)$ & $53.5(33-70)$ & .8 \\
\hline NYHA class $1(\%)$ & $7(9)$ & $8(10)$ & .81 \\
\hline NYHA class $2(\%)$ & $7(9)$ & $5(6)$ & \\
\hline NYHA class $3(\%)$ & $52(67)$ & $56(72)$ & \\
\hline NYHA class $4(\%)$ & $12(15)$ & $9(12)$ & \\
\hline Sinus rhythm $(\%)^{*}$ & $58(74)$ & $58(74)$ & 1 \\
\hline Karnofsky Index & $80.4(80-90)$ & $80.3(80-90)$ & .9 \\
\hline \multicolumn{4}{|l|}{ Comorbidity } \\
\hline Arterial hypertension $(\%)$ & $74(95)$ & $70(90)$ & .4 \\
\hline $\begin{array}{l}\text { Coronary artery disease } \\
(\%)^{*}\end{array}$ & $48(62)$ & $50(64)$ & .9 \\
\hline $\begin{array}{l}\text { Pulmonary hypertension } \\
(\%)^{*}\end{array}$ & $31(40)$ & $33(42)$ & .9 \\
\hline $\operatorname{COPD}(\%)^{*}$ & $11(14)$ & $10(13)$ & 1 \\
\hline Renal insufficiency $(\%) *$ & $15(19)$ & $14(18)$ & 1 \\
\hline Hemodialysis $(\%)$ & $2(3)$ & $4(5)$ & .7 \\
\hline Status post-stroke $(\%)^{*}$ & $7(9)$ & $7(9)$ & 1 \\
\hline \multicolumn{4}{|l|}{ Medication } \\
\hline Beta-blocker (\%) & $55(71)$ & $56(72)$ & 1 \\
\hline ACE inhibitor (\%) & $45(58)$ & $45(58)$ & 1 \\
\hline Calcium antagonist $(\%)$ & $13(17)$ & $11(14)$ & .8 \\
\hline Diuretic $(\%)^{*}$ & $58(74)$ & $58(74)$ & 1 \\
\hline Acetyl salicylic acid (\%) & $31(40)$ & $32(41)$ & 1 \\
\hline Amiodarone $(\%)$ & $1(1)$ & $5(6)$ & .2 \\
\hline Statin $(\%)$ & $34(44)$ & $36(46)$ & .9 \\
\hline \multicolumn{4}{|l|}{ Intraoperative } \\
\hline \multicolumn{4}{|l|}{ Procedure type $(\%)$} \\
\hline CABG operations* & $42(54)$ & $43(55)$ & 1 \\
\hline Valve operations & $51(65)$ & $52(67)$ & 1 \\
\hline $\begin{array}{l}\text { Pulmonary thrombo- } \\
\text { endoarterectomy* }\end{array}$ & $5(6)$ & $5(6)$ & 1 \\
\hline Combination surgery & $31(40)$ & $31(40)$ & 1 \\
\hline Redo CABG or valve & $14(18)$ & $19(24)$ & .4 \\
\hline Operation time (min) & $215.6(135-295)$ & $206.2(133-270)$ & .4 \\
\hline CPB time $(\mathrm{min})^{*}$ & $114.0(65-165)$ & $106.0(70-144)$ & .4 \\
\hline AXC time $(\min )^{*}$ & $71.6(41-104)$ & $68.4(43-100)$ & .6 \\
\hline $\mathrm{HCA}(\%)$ & $12(15)$ & $15(19)$ & .7 \\
\hline HCA (min) & $16.5(6-29)$ & $16.3(8-28)$ & 1 \\
\hline
\end{tabular}

Data are expressed as mean with 15th and 85 th percentile. NOMI, Nonocclusive mesenteric ischemia; euroSCORE, European System for Cardiac Operative Risk Evaluation; NYHA, New York Heart Association; COPD, chronic obstructive pulmonary disease; $A C E$, angiotensin-converting-enzyme; $C A B G$, coronary artery bypass grafting; $C P B$, cardiopulmonary bypass; $A X C$, aortic crossclamp; $H C A$, hypothermic circulatory arrest. *Matched variables.
TABLE 2. Relevant outcome parameters of the 78 patients with nonocclusive mesenteric ischemia in comparison with the control group

\begin{tabular}{lccr}
\hline \multicolumn{1}{c}{ Outcome } & $\begin{array}{c}\text { NOMI } \\
(\mathbf{n = 7 8 )}\end{array}$ & $\begin{array}{c}\text { Control } \\
(\mathbf{n = 7 8 )}\end{array}$ & $\begin{array}{c}\boldsymbol{P} \\
\text { value }\end{array}$ \\
\hline Mechanical ventilation (h) & $166.5 \pm 206.1$ & $63.4 \pm 170.0$ & $<.001$ \\
IABP support (\%) & $13(17)$ & $1(1)$ & .001 \\
Reexploration for & $18(23)$ & $2(3)$ & $<.001$ \\
$\quad$ bleeding (\%) & & & \\
Renal replacement & $42(53.4)$ & $5(6.4)$ & $<.001$ \\
$\quad$ therapy (\%) & & & \\
LOS ICU (d) & $9.3 \pm 9.3$ & $4.5 \pm 7.4$ & $<.001$ \\
LOS IMCU (d) & $6.1 \pm 5.1$ & $3.0 \pm 3.1$ & .001 \\
LOS hospital (d) & $20.2 \pm 12.4$ & $16.0 \pm 10.7$ & .032 \\
30-d mortality (\%) & $17(22.2)$ & $4(5.1)$ & .002 \\
\hline Dar
\end{tabular}

Data are expressed as mean \pm standard deviation. NOMI, Nonocclusive mesenteric ischemia; $I A B P$, intra-aortic balloon pump; $L O S$, length of stay; $I C U$, intensive care unit; $I M C U$, intermediate care unit.

\section{RESULTS}

After matching of patients with and without NOMI, there were no significant differences between the 2 groups with respect to demographics, comorbidity, preoperative medication, or intraoperative variables (Table 1). Patients with NOMI had a significantly longer requirement for mechanical ventilation and higher 30-day mortality. Postoperative length of stay in the hospital was significantly prolonged when compared with the control patients (Table 2).

\section{Comparison of Endothelin-1 Serum Concentrations in Patients With and Without Nonocclusive Mesenteric Ischemia}

Patients who had NOMI had significantly higher ET-1 serum levels preoperatively when compared with control patients (NOMI vs control patients: 11.3 vs 9.3 $\mathrm{pg} / \mathrm{mL} ; P=.001)$. The same was found for postoperative ET-1 serum levels (NOMI vs control patients: 15.7 vs 11.1 $\mathrm{pg} / \mathrm{mL}, P<.001$ ) (Figure 1). The increase from preoperative to postoperative ET-1 levels was higher in patients with NOMI than in control individuals $\left(P=.007 ; \eta_{\mathrm{p}} 2=0.05\right)$.

ORs were calculated by logistic regression. Patients were at higher risk to have NOMI with each increase of $1 \mathrm{pg} / \mathrm{mL}$ ET-1 preoperatively (OR, $1.17 ; 95 \%$ confidence interval [CI], 1.06-1.29) and postoperatively (OR, 1.26; 95\% CI, 1.14-1.39). Even after adjustment for potential preoperative and intraoperative confounders (Table 3), preoperative (OR, $1.19 ; 95 \% \mathrm{CI}, 1.06-1.39)$ and postoperative (OR, 1.38; 95\% CI, 1.21-1.58) ET-1 levels remained an independent risk factor for NOMI.

ROC analyses of preoperative ET-1 serum levels and the occurrence of NOMI revealed an optimal cutoff value of 
TABLE 3. Odds ratios of endothelin-1 for the development of nonocclusive mesenteric ischemia: Logistic regression analyses for the development of nonocclusive mesenteric ischemia according to preoperative or postoperative endothelin-1 serum levels

\begin{tabular}{|c|c|c|c|c|c|c|}
\hline & \multicolumn{3}{|c|}{ After ET-1 } & \multicolumn{3}{|c|}{ Before ET-1 } \\
\hline & OR & $95 \% \mathrm{CI}$ & Chi-square ( $P$ value $)$ & OR & $95 \%$ CI & Chi-square ( $P$ value) \\
\hline Crude & 1.26 & $1.14-1.39$ & $30.78(<.001)$ & 1.17 & $1.06-1.29$ & $11.73(.001)$ \\
\hline Adjusted 1 & 1.33 & $1.18-1.51$ & $50.43(.003)$ & 1.18 & $1.06-1.32$ & $25.03(.520)$ \\
\hline Adjusted 2 & 1.38 & $1.21-1.58$ & $61.31(.001)$ & 1.19 & $1.06-1.39$ & $31.34(.500)$ \\
\hline Adjusted $2+1$ risk factor* & 1.38 & $1.21-1.58$ & $61.63(.002)$ & 1.19 & $1.06-1.34$ & $31.62(.534)$ \\
\hline Adjusted $2+2$ risk factors $\dagger$ & 1.66 & $1.37-2.02$ & $98.13(<.001)$ & 1.27 & $1.11-1.45$ & $53.41(.018)$ \\
\hline Adjusted $2+3$ risk factors $\ddagger$ & 2.04 & $1.54-2.72$ & $120.65(<.001)$ & 1.29 & $1.12-1.49$ & $70.66(<.001)$ \\
\hline
\end{tabular}

\begin{tabular}{|c|c|c|c|c|c|c|}
\hline & \multicolumn{3}{|c|}{ After cutoff ET-1 } & \multicolumn{3}{|c|}{ Before cutoff ET-1 } \\
\hline & OR & $95 \%$ CI & Chi-square ( $P$ value) & OR & $95 \%$ CI & Chi-square $(P$ value $)$ \\
\hline Crude & 12.00 & $4.67-30.83$ & $37.00(<.001)$ & 4.71 & $2.16-10.26$ & $17.13(<.001)$ \\
\hline Adjusted 1 & 26.71 & 8.01-89.09 & $59.23(<.001)$ & 5.26 & $2.25-12.30$ & $30.99(.229)$ \\
\hline Adjusted 2 & 36.80 & $10.18-133.10$ & $70.02(<.001)$ & 5.19 & $2.17-12.40$ & $36.85(.254)$ \\
\hline Adjusted $2+1$ risk factor* & 36.92 & $10.21-133.47$ & $70.11(<.001)$ & 5.19 & $2.17-12.40$ & $36.86(.295)$ \\
\hline Adjusted $2+2$ risk factors $\dagger$ & 313.53 & $40.37-2435.15$ & $98.13(<.001)$ & 6.37 & $2.29-17.70$ & $56.95(.008)$ \\
\hline Adjusted $2+3$ risk factors $\ddagger$ & 362.13 & $35.56-3687.06$ & $117.53(<.001)$ & 7.23 & $2.81-18.98$ & $70.45(<.001)$ \\
\hline
\end{tabular}

Data are expressed as OR with $95 \%$ CI. 1. Adjusted for gender, age, weight, European System for Cardiac Operative Risk Evaluation, ejection fraction, sinus rhythm, coronary artery disease, pulmonary hypertension, chronic obstructive pulmonary disease, renal insufficiency, status post-stroke, and diuretic. 2. Adjusted for all variables of (1) and coronary artery bypass graft operations, pulmonary thrombo-endoarterectomy, CPB time, and hypothermic circulatory arrest. OR, Odds ratio; $C I$, confidence interval; ET-1, endothelin-1. *Adjusted $2+1$ risk factor (loss of sinus rhythm). $\dagger$ Adjusted $2+2$ risk factors (loss of sinus rhythm and need for norepinephrine $>0.1 \mu \mathrm{g} / \mathrm{kg} / \mathrm{min}$ ). $\ddagger$ Adjusted $2+3$ risk factors (loss of sinus rhythm, need for norepinephrine $>0.1 \mu \mathrm{g} / \mathrm{kg} / \mathrm{min}$ and intra-aortic balloon pump).

$11.7 \mathrm{pg} / \mathrm{mL}$ with an area under the curve of $0.67(95 \% \mathrm{CI}$, $0.58-0.75 ; P<.001)$, a sensitivity of $44 \%$, and a specificity of $85 \%$. ROC analyses of postoperative ET-1 serum levels showed an optimal cutoff value of $14.5 \mathrm{pg} / \mathrm{mL}$ with an area under the curve of 0.77 (95\% CI, $0.69-0.84 ; P<.001)$, a sensitivity of $51 \%$, and a specificity of $94 \%$ (Figure 2). Patients with ET-1 levels above the preoperative and postoperative cutoff values had an increased risk to have

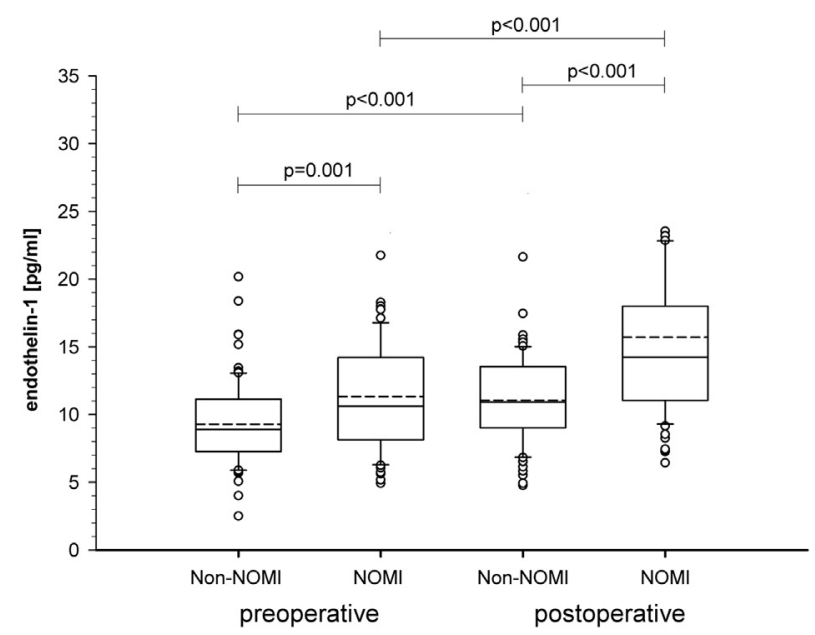

FIGURE 1. ET-1 serum levels. Comparison of ET-1 serum levels in patients with NOMI postoperatively versus a 1:1 matched control group. Samples were taken in the afternoon the day before and the morning after surgery. Short dash $=$ mean values of ET-1. Solid dash $=$ median values of ET-1. The box represents the 25th and 75th percentiles. Each separate point represents an outlier. NOMI, Nonocclusive mesenteric ischemia.
NOMI of 4.7-fold (OR, 4.71; 95\% CI, 2.16-10.26) and 12 -fold (OR, 12.00; 95\% CI, 4.67-30.83), respectively. After adjustment for potential preoperative and intraoperative confounders (Table 3), the risk preoperatively was 5-fold (OR, 5.19; 95\% CI, 2.17-12.40) and the risk

\section{PREDICTIVE VALUE OF ET-1 IN NOMI}

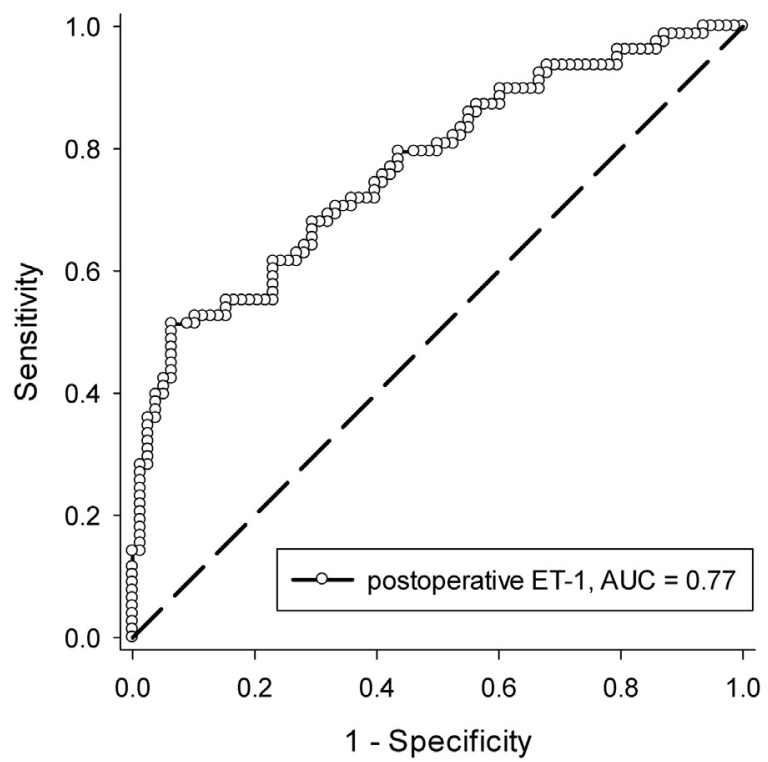

FIGURE 2. ROC curve analysis for predictive capacity of postoperative serum ET-1 level for NOMI. ET-1, Endothelin 1; NOMI, nonocclusive mesenteric ischemia; $A U C$, area under the curve. 
TABLE 4. Perioperative risk factors and endothelin-1 serum levels

\begin{tabular}{|c|c|c|c|}
\hline Risk factor & $\begin{array}{l}\text { NOMI } \\
(\mathbf{n})\end{array}$ & $\begin{array}{c}\text { Control } \\
\text { (n) }\end{array}$ & $\begin{array}{c}P \\
\text { value }\end{array}$ \\
\hline \multicolumn{4}{|c|}{ Postoperative ET-1 serum levels (pg/ml) } \\
\hline $\begin{array}{l}\text { Postoperative IABP } \\
\text { support }\end{array}$ & $15.7 \pm 8.0(13)$ & $7.5(1)$ & - \\
\hline Reexploration for bleeding & $17.7 \pm 12.4(23)$ & $9.9 \pm 5.8(2)$ & - \\
\hline $\begin{array}{l}\text { Postoperative need for } \\
\text { more than } 2 \text { PRBC }\end{array}$ & $16.4 \pm 10.3(48)$ & $11.2 \pm 3.4(28)$ & .002 \\
\hline $\begin{array}{l}\text { Postoperative serum lactate } \\
\text { level }>5 \mathrm{mmol} / \mathrm{L}\end{array}$ & $17.1 \pm 11.9(29)$ & $9.9 \pm 2.4(7)$ & .007 \\
\hline $\begin{array}{l}\text { Postoperative need for } \\
\text { norepinephrine } \\
>0.1 \mu \mathrm{g} / \mathrm{kg} / \mathrm{min}\end{array}$ & $13.5 \pm 3.9(38)$ & $10.8 \pm 3.7(17)$ & .02 \\
\hline $\begin{array}{l}\text { Postoperative levosimendan } \\
\text { therapy }\end{array}$ & $11.3 \pm 2.8(9)$ & $0(0)$ & - \\
\hline $\begin{array}{l}\text { Postoperative loss of sinus } \\
\text { rhythm }\end{array}$ & $17.3 \pm 10.3(44)$ & $11.2 \pm 2.8(44)$ & $<.001$ \\
\hline
\end{tabular}

Comparison of ET-1 serum concentrations in patients with NOMI and patients at risk for the development of NOMI. Data are expressed as mean \pm standard deviation. NOMI, Nonocclusive mesenteric ischemia; IABP, intra-aortic balloon pump; $P R B C$, packed red blood cells.

postoperatively was 37-fold (OR, 36.80; 95\% CI, 10.18-133.10).

\section{Endothelin-1 Serum Levels in Patients With Perioperative Risk Factors for Nonocclusive Mesenteric Ischemia}

The comparison of control patients and patients with NOMI with least 1 of the 7 risk factors for NOMI showed significantly increased postoperative ET-1 serum levels for those with NOMI. This was true irrespective of the risk factor (Table 4). We observed 18 control patients with ET-1 serum levels above the determined cutoff value. However, they had no profile of risk factors. Of the latter, none died, and the postoperative course was uneventful.

After adjustment for confounding postoperative risk factors (loss of sinus rhythm, norepinephrine therapy $>0.1 \mu \mathrm{g} / \mathrm{kg} / \mathrm{min}$, intra-aortic balloon pump), preoperative (OR, 1.29; 95\% CI, 1.12-1.49) and postoperative (OR, 2.04; 95\% CI, 1.54-2.72) ET-1 levels remained an independent risk factor for NOMI (Table 3).

Patients with at least 1 clinical risk factor and ET-1 levels above the preoperative and postoperative cutoff values had an increased risk of developing NOMI of 7.2-fold for preoperative elevation (OR, 7.23; 95\% CI, 2.81-8.98) and 362-fold for postoperative elevation (OR, 362.13; 95\% CI, 35.56-3687.06).

\section{DISCUSSION}

The incidence of gastrointestinal complications after cardiac surgery with CPB has been reported to range from $0.79 \%$ to $4.1 \%{ }^{1,8}$ Some of them are well recognized, such as upper gastrointestinal bleeding and gastric or colon perforation. ${ }^{1,9,10}$ Less well recognized is the occurrence of NOMI, which is associated with mortality rates of up to $90 \% \cdot{ }^{1,2,11} \mathrm{NOMI}$ is a seemingly rare entity, most likely because of its nature as a difficult clinical problem due to the nonspecific nature of the symptoms and difficulty in diagnosis. It presents with a variable clinical picture, ranging from oliguria to a marked increase in vasopressor demand, severe oxygenation deficit, or the typical scenario of ileus and obvious small bowel gangrene found at surgery or autopsy. Abdominal pain is often suppressed by analgosedation early after cardiac surgery. ${ }^{12,13}$ The nonspecific changes (hypoxia, oliguria, or hypotension refractory to vasopressor administration) may easily be interpreted as sepsis or beginning multiorgan failure. Only angiography performed in the presence of normal cardiac output will allow the diagnosis of NOMI as the underlying disease.

Thus, angiography is required for diagnosis; intra-arterial infusion of vasodilators through the angiography catheter currently is the only treatment option. The key in treating NOMI successfully lies in high suspicion based on clinical parameters, liberal decision in favor of angiography, and thus early treatment. ${ }^{14}$ However, angiography is an invasive study and not always readily available. To decrease the high mortality of patients with NOMI, it would be useful to identify patients at an increased risk. Perioperative risk factors for the development of NOMI after elective cardiac surgery have been found, such as intra-aortic balloon pump, catecholamine support, or CPB time. ${ }^{4}$ On the other hand, none of the factors explain a possible mechanism that links $\mathrm{CPB}$ and NOMI.

The exact pathomechanism leading to nonocclusive disease is currently unknown. ${ }^{2,4}$ Moreover, it is unclear whether NOMI is simply the delayed result of microcirculatory alterations initiated during $\mathrm{CPB}$ or the manifestation of a separate disease. In line with previously published data, ${ }^{15-17}$ we recently showed in an experimental model that CPB may induce significant alterations in the microcirculation of the mesenteric vascular bed. ${ }^{7}$ These are most pronounced in the small bowel, particularly in the terminal ileum ${ }^{2}$; this is also the part of the intestinal tract that is most commonly and severely affected when angiography is performed in the presence of NOMI. ${ }^{3}$

Irrespective of the anatomic variabilities, we found upregulation of ET receptors and an increase in ET-1 in mesenteric tissue during CPB and mesenteric ischemia. Likewise, Bond and colleagues ${ }^{18}$ observed generally increased ET-1 levels after cardiac surgery, although they did not investigate the possible occurrence of NOMI. We hypothesized that ET-1 may be an independent risk factor for the development of NOMI and decided to study whether the occurrence of NOMI is related to elevated serum ET-1 levels. 
We previously initiated a prospective cohort study to investigate the risk factors for NOMI after elective cardiac surgery. ${ }^{4}$ In this cohort of 865 patients, 78 developed NOMI. Because we had obtained different preoperative biochemical parameters on all patients, these study patients seemed ideal to investigate the role of ET in the context of NOMI. To create an adequate control group, we decided to use matched groups. Patients from the study cohort with and without NOMI were matched regarding demographics, comorbidity, preoperative medication, and intraoperative variables via a propensity score. After matching, there were no significant differences between the 2 groups with respect to preoperative and intraoperative parameters. Despite the usual heterogeneity in clinical investigations, matching resulted in groups that were comparable with respect to known clinical risk factors for the development of NOMI, particularly renal insufficiency and $\mathrm{CPB}$ time. ${ }^{4}$

The most impressive finding was the statistically significant link between elevation of ET levels and risk of NOMI. Preoperative ET-1 levels were significantly increased in patients with NOMI in both univariate (NOMI vs control patients: $11.3 \mathrm{vs} 9.3 \mathrm{pg} / \mathrm{mL} ; P=.001$ ) and multivariate analyses (OR, 1.19; 95\% CI, 1.06-1.39). Elevation of the preoperative ET above the cutoff level of $11.7 \mathrm{pg} / \mathrm{mL}$ increased the risk of NOMI by 5-fold. Of note, patients with NOMI had an even more pronounced increase in postoperative ET-1 serum levels. It is thus conceivable that preoperative activation of the ET system predisposes to the development of postoperative NOMI.

Increased ET levels alone seem to be a risk factor. In combination with 3 independent clinical risk factors 4 (loss of sinus rhythm, need for norepinephrine $>0.1 \mu \mathrm{g} / \mathrm{kg} / \mathrm{min}$, and intra-aortic balloon pump), we found a stepwise increase of the probability of developing NOMI. We calculated the effect of these additional factors (Table 3) and could confirm the increased risk. In the presence of 3 risk factors and elevation of ET-1, the probability of NOMI was increased by 7 -fold. The fact that postoperative ET-1 levels were also significantly increased in patients with proven NOMI in univariate and multivariate analyses (OR, 12.00; 95\% CI, 4.67-30.83) suggests that determination of postoperative ET-1 levels may identify patients at highest risk for early angiography.

There is evidence that circulating levels of ET-1 are increased in patients with terminal renal failure, ${ }^{19,20}$ essential hypertension, ${ }^{21}$ myocardial infarction, ${ }^{22}$ heart failure, ${ }^{23}$ and pulmonary hypertension. ${ }^{24}$ All these factors, alone or in combination, are more frequent in patients undergoing cardiac surgery compared with the general population. These factors provide a possible pathophysiologic link between the known clinical risk factors and the current observations regarding NOMI, ${ }^{25,26}$ indicating that the ET system is involved in the pathogenesis of NOMI. In summary, preoperatively elevated ET-1 serum levels indicate an individualized increased susceptibility to the development of NOMI in patients undergoing elective cardiac surgery.

Our results are in line with the knowledge about impaired jejunal microcirculation during CPB and the known effects of ET. In a porcine model, experimental application of ET-1 has been shown to reduce microvascular blood flow of the distal jejunum. ${ }^{5}$ Specific $\mathrm{ET}_{\mathrm{A}}$ and $\mathrm{ET}_{\mathrm{B}}$ blockade with tezosentan was shown to improve microcirculatory blood flow in the ileal mucosa during experimental endotoxemia. ${ }^{6}$ Previous studies showed that ET-1 is elevated during acute mesenteric ischemia in rats. ${ }^{27}$ ET-receptor antagonists had a protective effect in ischemia-reperfusion injury of the small bowel. ${ }^{28,29}$ These observations indicated a role of ET in visceral malperfusion in animal studies. We now observed an association between the ET-1 serum levels and the occurrence of NOMI in patients after elective cardiac surgery.

Although the 30-day mortality was elevated in our cohort (NOMI 22\% vs control 5\%), it can be assumed that without angiography and treatment of NOMI, the majority of patients with NOMI would have died. The actual mortality plus the possible NOMI mortality would still reach a cumulative mortality that is well within the expected range according to current databases (eg, Society of Thoracic Surgeons). In hospitals that are not "tuned to" the possibility of NOMI, these patients are likely to have died from "sepsis/multiorgan failure."

\section{Study Limitations}

The design of the current study does not provide causal proof of such a mechanism. Further studies will be required to elucidate stepwise the physiologic connections. If ET-1 proves to be a major player in the development of NOMI after cardiac surgery, interventional studies investigating the effect of ET-1 receptor antagonists could be considered. Further studies are needed to define cutoff points with groups of a bigger size and to incorporate ET-1 levels in useful prediction models.

Another limitation of our study is that the control group (patients without NOMI) did not undergo angiography. However, NOMI will likely result in death if not treated, and this commonly occurs in the first 10 days after surgery. Only 4 control patients died within the first 30 postoperative days; in addition, none of these patients died within the first 10 days after surgery. These considerations make the occurrence of NOMI in the control group unlikely.

\section{CONCLUSIONS}

Preoperative and postoperative ET-1 serum levels are elevated in patients with NOMI after elective cardiac surgery. Therefore, ET-1 may be a useful marker to identify patients at risk for NOMI before and after cardiac surgery. 
ET also may be the physiologic link explaining the occurrence of NOMI after cardiac surgery.

The authors thank Doris Bandner-Risch for support in the laboratory.

\section{References}

1. Geissler HJ, Fischer UM, Grunert S, Kuhn-Regnier F, Hoelscher A, Schwinger RH, et al. Incidence and outcome of gastrointestinal complications after cardiopulmonary bypass. Interact Cardiovasc Thorac Surg. 2006;5:239-42.

2. Klotz S, Vestring T, Rotker J, Schmidt C, Scheld HH, Schmid C. Diagnosis and treatment of nonocclusive mesenteric ischemia after open heart surgery. Ann Thorac Surg. 2001;72:1583-6.

3. Minko P, Groesdonk H, Stroeder J, Miodek J, Graeber S, Bucker A, et al. A scoring system for the assessment of angiographic findings in non-occlusive mesenteric ischemia (NOMI). Rofo. 2012;184:805-9.

4. Groesdonk HV, Klingele M, Schlempp S, Bomberg H, Schmied W, Minko P, et al. Risk factors for nonocclusive mesenteric ischemia after elective cardiac surgery. J Thorac Cardiovasc Surg. 2013;145:1603-10.

5. Nankervis CA, Schauer GM, Miller CE. Endothelin-mediated vasoconstriction in postischemic newborn intestine. Am J Physiol Gastrointest Liver Physiol. 2000;279:G683-91.

6. Andersson A, Fenhammar J, Weitzberg E, Sollevi A, Hjelmqvist H, Frithiof R. Endothelin-mediated gut microcirculatory dysfunction during porcine endotoxaemia. Br J Anaesth. 2010;105:640-7.

7. Bomberg H, Bierbach B, Flache S, Wagner I, Glaser L, Groesdonk HV, et al. Endothelin and vasopressin influence splanchnic blood flow distribution during and after cardiopulmonary bypass. J Thorac Cardiovasc Surg. 2013;145:539-47.

8. Rodriguez F, Nguyen TC, Galanko JA, Morton J. Gastrointestinal complications after coronary artery bypass grafting: a national study of morbidity and mortality predictors. J Am Coll Surg. 2007;205:741-7.

9. Andersson B, Nilsson J, Brandt J, Hoglund P, Andersson R. Gastrointestinal complications after cardiac surgery. Br J Surg. 2005;92:326-33.

10. Christenson JT, Schmuziger M, Maurice J, Simonet F, Velebit V. Gastrointestinal complications after coronary artery bypass grafting. J Thorac Cardiovasc Surg. 1994;108:899-906.

11. Filsoufi F, Rahmanian PB, Castillo JG, Scurlock C, Legnani PE, Adams DH Predictors and outcome of gastrointestinal complications in patients undergoing cardiac surgery. Ann Surg. 2007;246:323-9.

12. Howard TJ, Plaskon LA, Wiebke EA, Wilcox MG, Madura JA. Nonocclusive mesenteric ischemia remains a diagnostic dilemma. Am J Surg. 1996;171:405-8.

13. Bassiouny HS. Nonocclusive mesenteric ischemia. Surg Clin North Am. 1997;77: 319-26.

14. Trompeter M, Brazda T, Remy CT, Vestring T, Reimer P. Non-occlusive mesenteric ischemia: Etiology, diagnosis, and interventional therapy. Eur Radiol. 2002;12:1179-87.
15. Argenziano M, Chen JM, Choudhri AF, Cullinane S, Garfein E, Weinberg AD, et al. Management of vasodilatory shock after cardiac surgery: identification of predisposing factors and use of a novel pressor agent. J Thorac Cardiovasc Surg. 1998;116:973-80.

16. Khan TA, Bianchi C, Ruel M, Feng J, Sellke FW. Differential effects on the mesenteric microcirculatory response to vasopressin and phenylephrine after cardiopulmonary bypass. J Thorac Cardiovasc Surg. 2007; 133:682-8.

17. Tao W, Zwischenberger JB, Nguyen TT, Vertrees RA, McDaniel LB, Nutt LK, et al. Gut mucosal ischemia during normothermic cardiopulmonary bypass results from blood flow redistribution and increased oxygen demand. J Thorac Cardiovasc Surg. 1995;110:819-28.

18. Bond BR, Dorman BH, Clair MJ, Walker CA, Pinosky ML, Reeves ST, et al. Endothelin-1 during and after cardiopulmonary bypass: association to graft sensitivity and postoperative recovery. J Thorac Cardiovasc Surg. 2001;122: 358-64.

19. Koyama H, Tabata T, Nishzawa Y, Inoue T, Morii H, Yamaji T. Plasma endothelin levels in patients with uraemia. Lancet. 1989;1:991-2.

20. Ottosson-Seeberger A, Ahlborg G, Hemsen A, Lundberg JM, Alvestrand A. Hemodynamic effects of endothelin-1 and big endothelin-1 in chronic hemodialysis patients. J Am Soc Nephrol. 1999;10:1037-44.

21. Saito Y, Nakao K, Mukoyama M, Imura H. Increased plasma endothelin level in patients with essential hypertension. N Engl J Med. 1990;322: 205.

22. Watanabe T, Suzuki N, Shimamoto N, Fujino M, Imada A. Endothelin in myocardial infarction. Nature. 1990;344:114.

23. McMurray JJ, Ray SG, Abdullah I, Dargie HJ, Morton JJ. Plasma endothelin in chronic heart failure. Circulation. 1992;85:1374-9.

24. Stewart DJ, Levy RD, Cernacek P, Langleben D. Increased plasma endothelin-1 in pulmonary hypertension: marker or mediator of disease? Ann Intern Med. 1991;114:464-9.

25. Ende N. Infarction of the bowel in cardiac failure. N Engl J Med. 1958;258: 879-81.

26. Ori Y, Chagnac A, Schwartz A, Herman M, Weinstein T, Zevin D, et al. Non-occlusive mesenteric ischemia in chronically dialyzed patients: a disease with multiple risk factors. Nephron Clin Pract. 2005; 101:c87-93.

27. Wang JY, Cheng KI, Yu FJ, Tsai HL, Huang TJ, Hsieh JS. Analysis of the correlation of plasma no and et-1 levels in rats with acute mesenteric ischemia. J Invest Surg. 2006;19:155-61.

28. Lugowska-Umer H, Umer A, Sein-Anand J, Sokolowska-Wojdylo M, Wlodarkiewicz A, Korolkiewicz RP. Endothelin receptor blockers protect against ischemia/reperfusion impairment of gastrointestinal motility in rats. Pharmacol Res. 2008;57:413-8.

29. Oktar BK, Gulpinar MA, Bozkurt A, Ghandour S, Cetinel S, Moini H, et al. Endothelin receptor blockers reduce $\mathrm{i} / \mathrm{r}$-induced intestinal mucosal injury: role of blood flow. Am J Physiol Gastrointest Liver Physiol. 2002;282: G647-55. 
TABLE E1. Group characteristics of all 865 patients

\begin{tabular}{|c|c|c|c|}
\hline Risk factor & $\begin{array}{l}\text { NOMI } \\
(n=78)\end{array}$ & $\begin{array}{l}\text { Control } \\
(\mathbf{n}=787)\end{array}$ & $\begin{array}{c}P \\
\text { value }\end{array}$ \\
\hline \multicolumn{4}{|l|}{ Demographics } \\
\hline \multicolumn{4}{|l|}{ Gender $(\%)$} \\
\hline Female & $30(38)$ & $239(30)$ & .03 \\
\hline Male & $48(62)$ & $548(70)$ & \\
\hline Age (y) & $72.0(63-81)$ & $62.8(47-77)$ & $<.001$ \\
\hline Weight $(\mathrm{kg})$ & $81.7(65-98)$ & $82.3(66-97)$ & .002 \\
\hline Size $(\mathrm{cm})$ & $169.0(160-178)$ & $172.3(162-182)$ & .002 \\
\hline euroSCORE 2 & $10.6(2.8-21)$ & $5.8(1.3-9.7)$ & $<.001$ \\
\hline Ejection fraction $(\%)$ & $54.4(35-73)$ & $59.4(44-74)$ & .007 \\
\hline NYHA class $1(\%)$ & $7(9)$ & $42(5)$ & .002 \\
\hline NYHA class $2(\%)$ & $7(9)$ & $107(14)$ & \\
\hline NYHA class $3(\%)$ & $52(67)$ & $588(75)$ & \\
\hline NYHA class $4(\%)$ & $12(15)$ & $50(6)$ & \\
\hline Sinus rhythm $(\%)$ & $58(74)$ & $674(86)$ & .003 \\
\hline Karnofsky Index & $80.4(80-90)$ & $86.1(80-90)$ & .002 \\
\hline \multicolumn{4}{|l|}{ Comorbidity } \\
\hline Arterial hypertension (\%) & $74(95)$ & $691(88)$ & .24 \\
\hline Coronary artery disease $(\%)$ & $48(62)$ & $325(41)$ & $<.001$ \\
\hline Pulmonary hypertension $(\%)$ & $31(40)$ & $174(22)$ & $<.001$ \\
\hline COPD $(\%)$ & $11(14)$ & $53(7)$ & .02 \\
\hline Renal insufficiency $(\%)$ & $15(19)$ & $48(6)$ & $<.001$ \\
\hline Hemodialysis $(\%)$ & $2(3)$ & $13(2)$ & .56 \\
\hline Status poststroke $(\%)$ & $7(9)$ & $28(4)$ & .02 \\
\hline \multicolumn{4}{|l|}{ Medication } \\
\hline Beta-blocker (\%) & $55(71)$ & $521(66)$ & .44 \\
\hline ACE inhibitor $(\%)$ & $45(58)$ & $447(57)$ & .88 \\
\hline Calcium antagonist $(\%)$ & $13(17)$ & $119(15)$ & .74 \\
\hline Diuretic $(\%)$ & $58(74)$ & $346(44)$ & $<.001$ \\
\hline Acetylsalicylic acid (\%) & $31(40)$ & $237(30)$ & .10 \\
\hline Amiodarone $(\%)$ & $1(1)$ & $18(2)$ & .72 \\
\hline Statin $(\%)$ & $34(44)$ & $232(30)$ & .01 \\
\hline \multicolumn{4}{|l|}{ Intraoperative } \\
\hline \multicolumn{4}{|l|}{ Procedure type $(\%)$} \\
\hline CABG operations & $42(54)$ & $285(36)$ & .002 \\
\hline Valve operations & $51(65)$ & $549(70)$ & .44 \\
\hline $\begin{array}{l}\text { Pulmonary thrombo- } \\
\text { endoarterectomy }\end{array}$ & $5(6)$ & $23(3)$ & .17 \\
\hline Combination surgery & $31(40)$ & $252(32)$ & .21 \\
\hline Redo CABG or valve & $14(18)$ & $94(12)$ & .15 \\
\hline Operation time (min) & $215.6(135-295)$ & $166.7(119-217)$ & $<.001$ \\
\hline CPB time (min) & $114.0(65-165)$ & $82.8(52-111)$ & $<.001$ \\
\hline AXC time (min) & $71.6(41-104)$ & $54.4(33-74)$ & $<.001$ \\
\hline $\operatorname{HCA}(\%)$ & $12(15)$ & $86(11)$ & .26 \\
\hline HCA (min) & $16.5(6-29)$ & $13.3(6-24)$ & .49 \\
\hline
\end{tabular}

Data are expressed as mean with 15th and 85 th percentile. NOMI, Nonocclusive mesenteric ischemia; euroSCORE, European System for Cardiac Operative Risk Evaluation; NYHA, New York Heart Association; COPD, chronic obstructive pulmonary disease; $A C E$, angiotensin-converting-enzyme; $C A B G$, coronary artery bypass grafting; $C P B$, cardiopulmonary bypass; $A X C$, aortic crossclamp; $H C A$, hypothermic circulatory arrest. 
TABLE E2. Specific NOMI score system

\section{Criteria/score}

Vessel morphology
0 : None

1: Mild

2: Moderate

3: Severe

Contrast medium reflux into the aorta
0 : None
1: Mild
2: Severe

Contrasting of the parenchyma

0 : Complete

1: Some deficiency

2: Complete deficiency

Distension of the intestine
0 : None
1: Mild
2: Severe

Contrasting time of portal vein

0: Normal

1: Slightly delayed

2: Delayed

Total score

No

Mild (grade 1)

Moderate (grade 2)

Severe (grade 3)

\section{Description}

SMA trunk, branches, and mesenteric arcades normal

SMA trunk normal, several SMA branches, or mesenteric arcades slightly constricted SMA trunk slightly constricted, normal SMA branches, and mesenteric arcades

SMA trunk, several SMA branches, or mesenteric arcades slightly constricted

SMA trunk, multiple SMA branches, or mesenteric arcades constricted

SMA trunk, multiple SMA branches, or mesenteric arcades constricted

No contrast medium reflux into the aorta

Some contrast medium reflux into the aorta

Severe contrast medium reflux with complete aortogram

Homogeneous contrasting of the intestine

Inhomogeneous contrasting of the intestine

No contrasting of the intestine

Up to 3 air-containing, distended bowel loops

$>3$ air-containing, distended bowel loops

Ubiquitary distended bowel loops

SMA, Superior mesenteric artery.

$<8 \mathrm{sec}$

9-12 sec

$>13 \mathrm{sec}$

0

1-5

6-7

8-11 